\title{
Correction to: Intensification and Northward extension of Northwest Pacific anomalous anticyclone in El Niño decaying mid-summer: an energetic perspective
}

\author{
Haosu Tang ${ }^{1,3} \cdot \mathrm{Kaiming} \mathrm{Hu}^{1,2,4}(\mathbb{D}) \cdot$ Gang Huang ${ }^{1,2,3,4} \cdot \mathrm{Ya} \mathrm{Wang}^{1,3} \cdot$ Weichen Tao $^{1}$
}

Published online: 24 September 2021

(c) Springer-Verlag GmbH Germany, part of Springer Nature 2021

\section{Correction to: Climate Dynamics \\ https://doi.org/10.1007/s00382-021-05923-5}

In the original publication of the article the second corresponding author Kaiming Hu was not tagged. The author name Kaiming has been tagged in this erratum.

The original article has been corrected.

Publisher's Note Springer Nature remains neutral with regard to jurisdictional claims in published maps and institutional affiliations.

The original article can be found online at https://doi.org/10.1007/ s00382-021-05923-5.

\section{Kaiming $\mathrm{Hu}$}

hkm@mail.iap.ac.cn

$\triangle$ Gang Huang

hg@mail.iap.ac.cn

1 State key Laboratory of Numerical Modeling for Atmospheric Sciences and Geophysical Fluid Dynamics and Center for Monsoon System Research, Institute of Atmospheric Physics, Chinese Academy of Sciences, Beijing, China

2 Laboratory for Regional Oceanography and Numerical Modeling, Qingdao National Laboratory for Marine Science and Technology, Qingdao 266237, China

3 University of Chinese Academy of Sciences, Beijing 100049 , China

4 IAP/CAS, P.O. Box 9804, Beijing 100029, China 